\title{
The study of transient processes - a new direction in the development of a methodological approach to the solution of problems of complex development of geo- resources.
}

\author{
Victor Yakovlev ${ }^{1 *}$ \\ ${ }^{1}$ Institute of Mining, Ural Branch of the Russian Academy of Sciences, Ekaterinburg, Russia.
}

\begin{abstract}
The article presents the stages of technology development and methodology of subsoil development in the postwar years to the modern period, taking into account the transition from planned to market economy. The necessity of new methodological approaches to solving the problems of subsoil development based on the principles of consistency, complexity, interdisciplinary orientation. The definition of the strategy for the development of deep-lying complex structural fields with the increase of geological, mining and technical and economic information in the dynamics of mining. The concept of "transient processes" is introduced, the accounting of which laws is the basis for the development of innovative technologies for the evaluation, production and ore preparation of mineral raw materials that meet the requirements of the subsequent enrichment and metallurgical processes of production of commodity products. The features of development of reserves of deposits in the Northern and equated regions, including taking into account the integrated development of territories by creating mineral resource centers. The directions of further research of transient processes, focused on the establishment of the main factors affecting the justification of methods, stages and timing of adaptation of the parameters of the main technological processes in the existing mining enterprises to changing internal and external conditions of their operation and the development of new deep-seated deposits in different climatic and mining conditions. Keywords: Transient processes, complex development, complex field, methodological approach, innovative technology.
\end{abstract}

For quite a long 300-year period of mining development in Russia the greatest interest for the study of the historical experience of the development of scientific ideas, methodological approaches to the substantiation of the technologies, parameters of mining works and the strategy of exploitation of mineral resources of scientific publications in the

Corresponding author: yakovlev@,igduran.ru 
form of articles, monographs of eminent scholars in the field of mining Sciences academicians N. In. Melnikov, V. V. Rzhevsky, M. I. Agoshkova, doctors E. F. Sheshko, M. G. Novozhilov, A. I. Arsentiev, V. S. Khokhryakova and others, as well as the actual parameters and technical and economic indicators of mining enterprises in Russia and CIS countries over the past 50-70 years, i.e. for the period from the beginning of the transition to a complex-mechanized mining enterprises to modern mining and processing plants with a full cycle of technological processes of mining [1].

The continental part of the earth's crust, which is the source of all kinds of mineral raw materials, is represented by almost all the set of chemical elements with different background content, but they are all in a coherent aggregate state. All ferrous and nonferrous metals are oxidized, so the deposits created by nature are, as a rule, complex and have unique properties and parameters.

The need for research and accounting of transient processes in the technology of their development is due to the factors of natural variability of geological parameters of complex structural fields:

1. Occur in the form of veins, lenses, layers of variable power;

2. Mineral bodies contain inclusions of waste rock or substandard ores of different sizes and shapes, complicated by folded or discontinuous tectonic disturbances;

3. Power and elements of occurrence, stability of rocks, their fracturing, natural blockage, complexity, limits of strength and deformation properties vary widely;

4. The qualitative composition of the mineral changes, there is a natural or random zoning of the total balance of minerals, high unevenness of their content and granulometric composition from solid to fine-grained ores.

All this requires a detailed geometrization of placing a mineral in the bowels and taken into account when choosing mining equipment and technology, adaptive to changes of the geological environment, planning of mining works in the modes of selective dredging and averaging, the creation of innovative technologies of mining and ore preparation, taking into account patterns of transient processes when changing the operation conditions of the mining and processing enterprises. The specifics of the development of deep-lying complex structural deposits of solid minerals is that their development continues for decades, as a rule, begins open Geotechnology, in the conditions of continuous growth of the depth of the working area of the quarry, the growth of geological, mining and technological information, requiring unconditional allocation of stages of formation of career space, changes in the parameters of development systems, the formation of the transport system of the quarry through the use of new modes of transport, etc., that is, practically, revision of most of the design decisions, clarification of the depth of the quarry and, as a rule, the transition to underground or combined development of the field. The branch principle of development of unique fields with large reserves and the content of the main useful component did not demand methodical developments of the system account at carrying out geological prospecting works, justification of standards, the statement of stocks, design, construction and operation of the mining and processing enterprises.

In research and development of the subsoil development strategy should take into account the peculiarities of conditions for the development of mineral resources [2]:

1. Exhaustion and non-renewable reserves of specific mineral deposits.

2. The complexity of deposits and minerals.

3. Variety of natural conditions for the development of the same types of mineral raw materials.

4. The individuality of the technological properties and the conditions of processing of mineral raw materials.

5. High natural variability of geological parameters within a single field. 
6. Multiprocessing of mining production, dispersion and unsteadiness of the active part of the main fountains.

7. A variety of alternative ways to ensure a given volume of output.

8. Increase of information about the field as it is developed and making major decisions under uncertainty.

Factors of natural variability of geological parameters of complex structural deposits, substantiating the need for research and accounting of transient processes in the technology of their development:

1. Occur in the form of veins, lenses, layers of variable power;

2. Mineral bodies contain inclusions of waste rock or substandard ores of different sizes and shapes, complicated by folded or discontinuous tectonic disturbances;

3. Power and elements of occurrence, stability of rocks, their fracturing, natural blockage, complexity, limits of strength and deformation properties vary widely;

4. The qualitative composition of the mineral changes, there is a natural or random zoning of the total balance of minerals, high unevenness of their content and granulometric composition from solid to fine-grained ores.

All this requires a detailed geometrization of placing a mineral in the bowels and taken into account when choosing mining equipment and technology, adaptive to changes of the geological environment, planning of mining works in the modes of selective dredging and averaging, the creation of innovative technologies of mining and ore preparation, taking into account patterns of transition processes when changing the conditions of functioning of the mining enterprise. About the necessity of a radical revision of the current by the end of the $80 \mathrm{~s}$, ie, almost to the disintegration of the USSR, a methodological approach to solving a range of contemporary technical, technological and economic problems of the mining industry and mining Sciences very clearly set out in an unpublished, and presented in typewritten form in 1987. the report of academician V. V. Rzhevsky "Problems of mining Sciences (Confession of a mining engineer)". The measures taken in recent years in the Russian Academy of Sciences to consolidate the budget theme in the institutions, to concentrate the efforts of scientists on the most relevant scientific areas, to introduce a competitive principle of fundamental research on the programs of the RAS and its departments required the use of fundamentally new methodological approaches [3-5].

An example here is the program of the Presidium of the RAS, The Department of Earth Sciences, integration projects with the institutes of the mountain profile of Ural RAS, Siberia RAS and East region RAS. The institutes of Geology and Geochemistry, Geophysics, metallurgy, industrial ecology, ecology of plants and animals, Botanical garden take part in the implementation of the interdisciplinary project "development of the earth: prospects of expansion and complex development of ore mineral resources of the mining and metallurgical complex of the Urals", coordinated by the Institute of mining. At the present stage, when it is necessary to extract mineral raw materials on the deep horizons of the developed fields or to develop the resources of new regions, it is necessary to take into account the complexity of subsoil development (table.1).

The study of transient processes, the establishment of the causes of their occurrence, the understanding of the nature of the changes and the laws of their development in specific geological and mining conditions is the basis for the creation of a strategy for managing these processes during the entire period of development of deep-seated complex structural deposits - long-term action plan during the exploration, design and development to finished products on the basis of the methodological approach on the principles of consistency, complexity, interdisciplinarity and innovative direction, taking into account the increase in geological data of the Deposit when taking a pre-planned technological and technical solutions in response to changes in the internal and external conditions of functioning of the mining enterprise, including the regularities of their development in the adoption of 
innovative technologies for assessment production, ore preparation and enrichment of mineral raw materials. In the structural form, the new approaches are reduced to the combined application of program-target methods based on the principles of systematization, complexity and interdisciplinary research and their innovative orientation (table.2).

Table 1. Main difficulties of the current stage of subsoil development and ways of their accounting

\begin{tabular}{|c|c|}
\hline Complexities & Ways of accounting and solutions \\
\hline $\begin{array}{l}\text { The difference between the actual } \\
\text { geological structure of ore deposits } \\
\text { from the laid in the projects on the } \\
\text { basis of geological information (size, } \\
\text { shape, content, Phys.-fur. properties, } \\
\text { associated components, etc.). As a } \\
\text { result: low efficiency of technological } \\
\text { processes, loss of basic and associated } \\
\text { useful components }\end{array}$ & $\begin{array}{l}\text { Formation of database, creation of Deposit } \\
\text { model and methods of optimization of } \\
\text { parameters of mining enterprise and on their } \\
\text { basis: } \\
\text { - clarification of the boundaries and inventory; } \\
\text { - optimization of mining operations; } \\
\text { - modernization of technology and technology; } \\
\text { - reconstruction of the enterprise; } \\
\text { - complex development of mineral resources }\end{array}$ \\
\hline $\begin{array}{l}\text { Opening and working out of deep } \\
\text { horizons }\end{array}$ & $\begin{array}{l}\text { Creation of specialized loading and transport } \\
\text { equipment, technology for safe conduct of open } \\
\text { and underground mining }\end{array}$ \\
\hline Development of deposits of the North & $\begin{array}{l}\text { Development of a step-by-step strategy of } \\
\text { geological, technological and economic } \\
\text { justification of the parameters of future } \\
\text { enterprises }\end{array}$ \\
\hline
\end{tabular}

Table 2. The main principles of the methodological approach to the solution of problems of development of mineral resources

\begin{tabular}{|c|l|}
\hline Principle & \multicolumn{1}{|c|}{ Essence } \\
\hline System & $\begin{array}{l}\text { Disclosure of the basic rules of research, operation or development of } \\
\text { a mineral object, identification of various types of external and } \\
\text { internal relations that affect the construction of a generalized model } \\
\text { of the system under study }\end{array}$ \\
\hline Complexity & $\begin{array}{l}\text { Research of not only the phenomena and processes of development of } \\
\text { deposits, but also the possibility of the fullest use of all components } \\
\text { of mineral raw materials, development and development of territories } \\
\text { and regions of their location }\end{array}$ \\
\hline Interdisciplinarity & $\begin{array}{l}\text { Combining efforts in related fields of scientific knowledge for a } \\
\text { comprehensive assessment of the beneficial effect and the search for } \\
\text { innovative approaches to the use of mineral resources }\end{array}$ \\
\hline Innovative focus & $\begin{array}{l}\text { A mandatory requirement designed to provide a materialized result } \\
\text { obtained from investing in research, new technology or technology, } \\
\text { new forms of production organization, safety, management, etc. }\end{array}$ \\
\hline
\end{tabular}

Among the scientific, technological and organizational and technical issues to be solved in the design and development of complex structural fields of great depth, requiring the study of transient processes, are:

1. Assessment of the volume and quality of reserves, the decision on the expediency of their integrated development.

2. Substantiation of the method of development of a deep-seated field and the possibility (feasibility) of transition from open to underground or combined method.

3. Substantiation of the boundaries of the quarry, its depth, the angles of slope sides, the sequence of development of the working area, the allocation of stages of development. 
4. Formation of the transport system of the quarry in connection with the development of the quarry space and its working area, the use of new types, technical means and transport schemes with the replacement of existing, but more often in addition to them.

5. Stage-by-stage development of deposits, formation of temporarily non-working sides of quarries and their subsequent development with the use of special technologies and technical means of blasting, excavation, transport.

6. Opening of new horizons, including the possible change of physical and mechanical properties and material composition of the rock composing them.

7. Development of deposits of complex geological structure of the main mineral deposits in the presence of associated mineral components, significant variability of their content and other properties that require selective development, averaging and periodic changes in the parameters of development systems, ore preparation and enrichment.

Among the most important scientific, technological and organizational and technical issues to be solved in the design and development of complex structural fields of great depth, requiring the study of transients, are:

1. Assessment of the volume and quality of reserves, the decision on the expediency of their integrated development.

2. Substantiation of the method of development of a deep-seated field and the possibility (feasibility) of transition from open to underground or combined method.

3. Substantiation of the boundaries of the quarry, its depth, the angles of slope sides, the sequence of development of the working area, the allocation of stages of development.

4. Formation of the transport system of the quarry in connection with the development of the quarry space and its working area, the use of new types, technical means and transport schemes with the replacement of existing, but more often in addition to them.

5. Stage-by-stage development of deposits, formation of temporarily non-working sides of quarries and their subsequent development with the use of special technologies and technical means of blasting, excavation, transport.

6. Opening of new horizons, including the possible change of physical and mechanical properties and material composition of the rock composing them.

7. Development of deposits of complex geological structure of the main mineral deposits in the presence of associated mineral components, significant variability of their content and other properties that require selective development, averaging and periodic changes in the parameters of development systems, ore preparation and enrichment.

8. Transient processes associated with changes in the physical and mechanical properties of permafrost rocks (phase transitions when the air temperature from $+40^{\circ} \mathrm{C}$ to $60^{\circ} \mathrm{C}$ ), including in the sides of quarries and in the trunks of underground mines.

The necessity of application of innovative technological, technical and organizational decisions in transitional periods of field development it is possible to determine a continuous monitoring of the development of the mining system at all stages of development in connection with changing in time and space of the external and internal conditions of functioning of the mining enterprise.

The results of the research are published in articles and monographs, including collective ones, which reflect the current assessment of the state, innovative solutions and prospects for the development of mining Sciences and subsoil development [6-8].

New approaches to the development of the Northern subsoil are associated with the implementation of the strategy of accelerated gradual development of subsoil and the principle of integrated development of territories:

- accelerated, complex exploration and exploration of deposits;

- express geological, technological and economic assessment of mining and technical capabilities of each ore region; 
- creation of a geographical information system to assist with modeling and program complexes for the decision of technological, technical, environmental, economic etc. problems of designing and planning of mining (example: Tarynnahsky mine in Yakutia);

- priority of the goals of reducing the number of employees by increasing productivity and the abandonment of non-core and auxiliary industries;

- one management company (holding) in the territory of administrative education with a single industrial and social infrastructure (example: South Yakutia).

Basic principles of designing technologies for development of Northern fields:

- stages of mining operations;

- high-performance powerful equipment, equipment in the Northern performance;

- step-by-step transfer of mining equipment with diesel drive to electric;

- allocation of technological zones taking into account the cluster structure of ore deposits;

- organization of the operational testing system to optimize the processes of ore preparation and enrichment;

- integrated use of mineral resources by extracting the maximum of useful components and utilization of overburden and enrichment waste;

- an integrated approach to the development of the mining and machine-building complexes;

- advanced or parallel assessments that allow the results of work to be used in advance in the development of decisions, recommendations or the formulation of the main limiting conditions for subsoil use.

The main form of implementation of these principles is the creation of mineral resource centers [9].

\section{Conclusion}

The developed methodological approach based on the combined use of the principles of consistency, complexity, interdisciplinary and innovative orientation can be implemented by continuous monitoring of the development of mining and technological system of mining and processing enterprises, timely development of transient processes at all stages of development of the field and implementation of recommendations for improving the parameters and technologies requiring changes in connection with the changing internal and external. The main indicator characterizing the high degree of novelty of research is the further development of the program-target methodological approach to the study of the problems of subsoil development by introducing a fundamentally new concept of "transient processes" and taking into account the laws of their development in the development of innovative technologies for the extraction and ore preparation of mineral raw materials. The essence of novelty of the study of transient processes in the design and development of deep-seated deposits is that if the evaluation of dynamics of development of mining system and indicators of its functioning may need to change the parameters of the equipment or technology of the mining production, it is necessary to establish the need, the totality and consistency of a series of actions (events) to adopt and implement adopted innovative technological solutions. The proposed methodological approach, based on the study of transient processes is universal and can be used in the design of the development of deepseated deposits, the planning, organization and management of mining and ore dressing of mineral raw materials in existing mines given the growth of geological information, the implementation of the developed innovative events, changes of parameters and indicators of the mining system of the mining enterprise with the development of mining operations.

In general, the proposed methodological approach allows for a more complete account of geological, mining, environmental and organizational features of the assessed fields and 
their location areas, as well as to provide the prerequisites for the systematic adoption of the most effective energy- and resource-saving technological solutions.

The absence of the state strategic program for the development of the mineral resource base of the Russian Federation, the economy of which is $3 / 4$ associated with the use of mineral resources and their processing products, necessitates comprehensive research with the participation of geologists, miners, metallurgists, economists in the framework of the program of the Presidium of RAS "Strategy for the development of the mineral resource base of the Russian Federation as the basis of its economy and national security."

Further studies of transient processes are aimed at establishing the main factors affecting the justification of methods, stages and timing of adaptation of the parameters of the main technological processes in existing mining enterprises to changing internal and external conditions of their operation and the development of new deep-seated deposits in various natural and climatic and mining conditions.

\section{References:}

1. Yakovlev V. L. Problems of subsoil use. - № 3 [Electronic resource]: peer-reviewed collection of scientific articles. Ekaterinburg. P. 15 - 26. (2014). //trud.igduran.ru

2. Batugin S. A. Regularities of mining development. IGDS SB RAS. Yakutsk. $116 \mathrm{p}$. (1992).

3. Trubetskoy K. N. Mountain science. Development and conservation of the earth's interior.Publishing house of Academy of mining Sciences. - 478 p. (1997).

4. Yakovlev V. L. Methodological aspects of mineral resources development strategy. Ekaterinburg: IGD Uro ran. 152 p. (2001).

5. Trubetskoy K. N. Gorny Zhurnal. 1. P. 15 - 19. (2012).

6. Yakovlev V. L. Herald of Ural branch of RAS. Science. Society. Man. 4. P. 43 - 49. (2013).

7. V. L. Yakovlev, I. V. Sokolov, G. G. Sakantsev, I. L.Kravchuk. Gorn. 7. P. 46-50. (2017).

8. Yakovlev V. L. Problems of subsoil use. 2 [Electronic resource]: peer-reviewed collection of scientific articles. - Ekaterinburg: IGD Uro ran. P. 5 - 15. (2017). $/ /$ trud.igduran.ru

9. V. L. Yakovlev, S. V. Kornilkov, A. P. Van-Van-E, V. S. Litvintsev, G. F. Sklyarov, N. Lavrik, A. Problems of subsoil use. 3 [Electronic resource]: peer-reviewed collection of scientific articles. - Ekaterinburg: IGD Uro ran. P. 38 - 46. (2014). 